\title{
About the basis and limits \\ of criminalization of public spread \\ of knowingly false information \\ in the media and telecommunication \\ networks
}

\section{I. Balandin ${ }^{1}$}

${ }^{1}$ Samara National Research University, 34 Moskovskoye shosse, Samara 443086, Russian Federation

DOI: 10.18255/1996-5648-2021-3-398-407

Research article

Full text in Russian

Basis and limits of criminalization of spread of knowingly false information is proved in article. From the point of view of law enforcement, the author evaluates the legal technique of the corpus delicti of crimes in Articles 2071 and 2072 of the Criminal Code of the Russian Federation. In connection with the regulation of those spheres of public relations that previously did not need it, the study touches on certain aspects concerning the basis of criminal liability for the dissemination of deliberately false information about circumstances that pose a threat to the life and safety of citizens, or entailed serious consequences. Consider the separation of the components of administrative offences and criminal offences in connection with the public dissemination of false information in the media, information and telecommunication networks. The conclusion is made about the unjustified alternativeness of the studied compositions in criminal and administrative law, which complicates law enforcement practice. It also offers recommendations for resolving existing conflicts in legislative and law enforcement practice.

Keywords: structura of crime; public spread; covid; false information; media and telecommunication networks; criminal liability; criminalization; criminal policy

\section{INFORMATION ABOUT AUTHORS}

\author{
Balandin, Vladislav I. E-mail: bullkee@gmail.com \\ Assistant of the Department of Criminal Law \\ and Criminology of the Faculty of Law
}




\section{Об основаниях и пределах \\ криминализации публичного \\ распространения заведомо ложной \\ информации в СМИ и информационно- \\ телекоммуникационных сетях}

В. И. Баландин ${ }^{1}$

${ }^{1}$ Самарский национальный исследовательский университет имени академика С. П. Королева, Московское шоссе, 34, Самара, 443086, Российская Федерация

DOI: $10.18255 / 1996-5648-2021-3-398-407$

УДК 342.34

Научная статья

Полный текст на русском языке

В статье проанализированы основания и пределы криминализации деяний, связанных с публичным распространением заведомо ложной информации. С позиции правоприменения оценивается законодательная техника конструирования составов преступлений, закрепленных в ст. 2071, 2072 УК РФ. В связи с регулированием тех сфер общественных отношений, которые ранее в этом не нуждались, исследование затрагивает отдельные аспекты, касающиеся основания уголовной ответственности за распространение заведомо ложной информации об обстоятельствах, представляющих угрозу жизни и безопасности граждан либо повлекшие тяжкие последствия. Рассмотрен вопрос о разграничении составов административного правонарушения и уголовного преступления в связи с публичным распространением заведомо ложной информации в СМИ и информационно-телекоммуникационных сетях. Сделан вывод о необоснованной альтернативности исследуемых составов в уголовном и административном праве, что осложняет правоприменительную практику. Предложены рекомендации в целях разрешения существующих коллизионных ситуаций в законодательной и правоприменительной практике.

Ключевые слова: состав; публичное распространение; заведомо ложная информация; СМИ; информационно-телекоммуникационные сети; ответственность; криминализация; уголовная политика

\section{ИНФОРМАЦИЯ ОБ АВТОРАХ}

Баландин, Владислав Игоревич

E-mail: bullkee@gmail.com

Ассистент кафедры уголовного права

и криминологии Юридического фракультета

(C) Баландин В. И., 2021

Статья открытого доступа под лицензией CC BY (https://creativecommons.org/licenses/by/4.0/) 
Баландин В.И.

Современное российское уголовное право подвержено политизации $[1$, c. 55]. Стало обычным мотивировать криминализацию конкретных деяний политической целесообразностью и решением ситуационных задач государства.

В 2020 г. вспышка коронавирусной инфекции SARS-nCoV-2 вынудила государство оперативно реагировать на изменяющийся уклад жизни общества. В этих условиях появилась необходимость в правовой оценке новых деяний, которые ранее в ней не нуждались. Речь идет о распространении заведомо недостоверной, ложной информации о коронавирусе журналистами или гражданами через информационно-телекоммуникационную сеть Интернет, в том числе через социальные сети и приложения-мессенджеры. Такого рода информация получила в СМИ название «Fake news».

Ранее, весной 2019 г., были приняты поправки, дополняющие ст. $13^{15}$ КоАП РФ (Федеральный закон от 18.03.2019 № 27-ФЗ) в целях противодействия «фейкам» - недостоверной общественно значимой информации, распространяемой под видом достоверных сообщений и создающей угрозу для безопасности. При этом в 2019 г. дела об административных правонарушениях, предусмотренных ст. $13^{15}$ КоАП РФ, возбуждались органами внутренних дел крайне редко. Официальная статистика о количестве административных дел по ч. 9 ст. $13{ }^{15}$ КоАП РФ отсутствует, но опубликованы данные Международной правозащитной группы «Агора» о том, что в 2019 г. было выявлено 13 дел по различным «фейкам», в основном локального значения [2]. Такое незначительное количество дел подтверждало отсутствие политической мотивации для применения данной статьи.

Ситуация кардинально изменилась в конце марта 2020 г., когда для государственной власти стала очевидной угроза эпидемии и перед правоохранительными органами была поставлена задача реагировать на сопутствующие информационные угрозы. Так, в Следственном комитете и Министерстве внутренних дел РФ были созданы рабочие группы по мониторингу и опровержению в СМИ и сети Интернет заведомо ложной или непроверенной информации о фактах заражения или количестве инфицированных людей. 31 марта 2020 г. был принят и одобрен Советом Федерации, а на следующий день утвержден Президентом Российской Федерации законопроект № 929651-7, которым глава 24 УК РФ была дополнена ст. $207^{1}$ и $207^{2}$, устанавливающими уголовную ответственность соответственно за публичное распространение заведомо ложной информации об обстоятельствах, представляющих угрозу жизни и безопасности граждан, и за публичное распространение заведомо ложной общественно значимой информации, повлекшее тяжкие последствия. Причем новые статьи расположились следом за ст. 207 «Заведомо ложное сообщение об акте терроризма». Это отражает опасения государства по поводу возникновения паники у людей вследствие появления недостоверной информации. Очевидно, что контроль 
Об основаниях и пределах криминализации публичного распространения...

информации о распространении вируса и об эпидемии в целом стал именно политическим делом.

Возникают закономерные вопросы об общественной опасности этих новых криминализированных деяний. Об общественной опасности как ускользающем от внимания законодателей признаке преступления писали многие. Например, по мнению В. Е. ЖЖеребкина, поскольку общественная опасность не имеет заранее установленных признаков, законодатель при ее оценке не опирается на какие-либо точно определяемые понятия [3, с. 144]. Ю. Е. Пудовочкин заключает, что оценки законодателя о границах преступного и непреступного, как и всякие оценки, не лишены субъективизма, конъюнктурных соображений и возможных ошибок [4, с. 10]. Нужно согласиться и с И. Л. Честновым, утверждающим, что нет преступления и общественной опасности «самих по себе», есть деяния и явления, которые оцениваются определяющей систему ценностей доминирующей социальной группой как общественно опасные в контексте существующей культуры [5, с. 242].

В отношении влияния существующей иерархии ценностей на понимание общественно опасного возможен вывод, что посягательства на общественную и государственную безопасность только формально помещены в Особенной части УК РФ на «отдаленные места». На самом деле, государство их учитывает в первую очередь, а уже во вторую - интересы личности, ее права и свободы (за исключением жизни). Государство, направляя усилия на обеспечение общественной и государственной безопасности, может различными способами влиять на представления об общественной опасности, вплоть до манипулирования страхами и потребностями граждан, в том числе путем использования своих ресурсов (например, контролируемых СМИ) для формирования у людей необходимого общественного настроения и реакции на те или иные виды преступлений. И тогда акты криминализации получают общественную поддержку, уже невзирая на реальную опасность, которая исходит от деяний. Как следствие, есть возможность, что уголовное право из средства, призванного обеспечивать свободу личности, превратится в средство, эту свободу подавляющее.

Представители гражданского общества пристально следят за случаями осуждения по ст. $207^{1}$ и $207^{2}$ УК РФ, поскольку выраженные в этих статьях запреты воспринимаются как несущие угрозу праву на свободу мысли и слова, а неясность их содержания связывается с неограниченным усмотрением в процессе правоприменения.

По информации пресс-центра Министерства внутренних дел РФ, в 2020 г. зарегистрировано 37 преступлений по ст. $207^{1}$ УК РФ [6]. Первое уголовное дело возбуждено уже через два дня после вступления этой статьи в юридическую силу. Поводом стал пост в одном из местных сообществ в социальной сети «ВКонтакте» о том, что зараженного вирусом мужчину, якобы отпустили из больницы на общественном транспорте [7]. Официаль- 
Баландин В. И.

ных данных по возбуждению уголовных дел по ст. $207^{2}$ УК РФ за 2020 г. не имеется.

В правоприменительной практике сразу же была признана трудноразрешимой проблема разграничения преступлений, предусмотренных ст. $207^{1}$ и $207^{2}$ УК РФ. Настоящую проблему подтверждают результаты сравнительного анализа соответствующих составов преступлений.

Непосредственным объектом обоих преступлений признаны интересы общественной безопасности, интерпретируемые как состояние защищенности граждан и общества в целом от угроз, дестабилизирующих обычные и безопасные условия жизни общества. Официально криминализация объясняется тем, что именно этим интересам причиняется реальный вред либо создается реальная угроза его причинения. Новые уголовно-правовые запреты определяются как направленные на пресечение возбуждения в общественном сознании паники и страха, которые могут привести к серьезным последствиям в виде массовых волнений и беспорядков, насилия и человеческих жертв, имущественного вреда и других неблагоприятных последствий.

Вместе с тем для преступлений, предусмотренных в ст. 2071 и 2072 УК РФ, по-разному, но с позиции конкуренции определен предмет посягательства. Предмет посягательства в ст. 2072 УК РФ по своему охвату шире и включает в себя все признаки предмета посягательства, предусмотренного ст. 2071 УК РФ.

Для объективной стороны обоих преступлений характерно деяние в фрорме активных действий в виде публичного распространения заведомо ложной информации. Преступления реально различаются по признаку последствия. Состав преступления в ст. 2072 УК РФ по конструкции является материальным и предусматривает в качестве конструктивного признака наступление последствий в виде вреда здоровью человека, его смерти или иных тяжких последствий. Субъективное отношение лица к наступившим общественно опасным последствиям проявляется в фрорме неосторожной вины. В случае установления прямого или косвенного умысла лица по отношению к последствиям, деяние необходимо квалифицировать по направленности умысла как умышленное причинение вреда здоровью соответствующей тяжести, убийство или др. Если же указанные последствия не наступили, то при наличии других объективных признаков состава преступления деяние следует квалифицировать по ст. 2071 УК РФ, где состав по конструкции является формальным.

Субъективное отношение лица к совершенному деянию (даже в ст. $207^{2}$ УК РФ) характеризуется также наличием цели довести ложную инорормацию до сведения неопределённого круга лиц (более двух лиц, не являющихся соучастниками). Согласно положениям Обзора Президиума Верховного Суда РФ «По отдельным вопросам судебной практики, связанным с применением законодательства и мер по противодействию распростране- 
нию на территории Российской Федерации новой коронавирусной иноекции № 2», утв. Президиумом Верховного Суда РФ 30 апреля 2020 г., фрорма распространения (устная, письменная, с использованием технических средств) и средства (сообщение в СМИ, в сети Интернет, в мессенджерах, массовая рассылка электронных писем, выступление на митинге и др.) юридического значения не имеют. Признак публичности является оценочным и должен определяться правоприменителем с учетом всех обстоятельств совершенного деяния. Стоит обратить внимание на признание Верховным судом РФ публичным распространения информации из переписки в мессенджерах. Нетрудно сделать вывод, что здесь личная переписка оценена как публичная. Данное разъяснение возможно поставить под сомнение, поскольку в Конституции РФ каждому гарантируется тайна переписки (ч. 2 ст. 23).

Ещё один признак субъективной стороны рассматриваемых преступлений - заведомое знание виновного о ложном характере распространяемой информации. Данный признак следует особенно внимательно учитывать в случае, если лицо не является первоисточником ложной информации, а лишь ретранслирует (репостит) эти сведения в публичной плоскости. При этом правоприменителю в каждом случае следует исследовать вопрос о возможности признания деяния малозначительным.

Еще одна трудность - в разграничении соответствующих преступлений и административных правонарушений. Смежным по отношению к преступлению, предусмотренному в УК РФ в ст. $207^{1}$ «Публичное распространение заведомо ложной информации об обстоятельствах, представляющих угрозу жизни и безопасности граждан», является административное правонарушение, закрепленное в КоАП РФ в ч. 9 ст. $13^{15}$ «Распространение в средствах массовой информации, а также в информационно-телекоммуникационных сетях заведомо недостоверной общественно значимой инорормации под видом достоверных сообщений, создавшее угрозу причинения вреда жизни и (или) здоровью граждан, имуществу, угрозу массового нарушения общественного порядка и (или) общественной безопасности либо угрозу создания помех фрунционированию или прекращения фрункционирования объектов жизнеобеспечения, транспортной или социальной инфраструктуры, кредитных организаций, объектов энергетики, промышленности или связи, если эти действия лица, распространяющего информацию, не содержат уголовно наказуемого деяния».

Для разграничения смежных составов уголовного преступления и административного правонарушения применяется технико-юридический прием «исключение преступного». В ч. 9 ст. ст. $13^{15}$ КоАП РФ законодатель указывает: «Если эти действия лица, распространяющего информацию, не содержат уголовно наказуемого деяния». Здесь прямо не указана, но, очевидно, имеется в виду ст. $207^{1}$ УК РФ, где содержатся признаки смежного состава преступления. По буквальному толкованию статей разграни- 
Баландин В. И.

чительным признаком выступает предмет посягательства. Так, предметом правонарушения в ч. 9 ст. ст. $13^{15}$ КоАП РФ является общественно значимая информация, под которой понимается информация, которая «создает угрозу причинения вреда жизни и (или) здоровью граждан, имуществу, угрозу массового нарушения общественного порядка и (или) общественной безопасности либо угрозу создания помех фрункционированию или прекращения фрунццинирования объектов жизнеобеспечения, транспортной или социальной инфраструктуры, кредитных организаций, объектов энергетики, промышленности или связи». Предмет преступления, предусмотренного ст. $207^{1}$ УК РФ, - информация об обстоятельствах, представляющих угрозу жизни и безопасности граждан, и (или) о принимаемых мерах по обеспечению безопасности населения и территорий, приемах и способах защиты от указанных обстоятельств.

В Обзоре Президиума Верховного Суда РФ «По отдельным вопросам судебной практики, связанным с применением законодательства и мер по противодействию распространению на территории Российской Федерации новой коронавирусной инфекции № 1», утв. Президиумом Верховного Суда РФ 21 апреля 2020 г., к общественно значимой информации (предмет административного правонарушения, предусмотренного ч. 9 ст. $13^{15}$ КоАП РФ) отнесена также инфрормация об обстоятельствах, представляющих угрозу жизни и безопасности граждан, и (или) о принимаемых в связи с этим мерах по обеспечению безопасности населения и территорий, приемах и способах защиты от указанных обстоятельств (предмет преступления, предусмотренного ст. $207^{1}$ УК РФ).

С учетом логики «исключения преступного», предмет административного правонарушения, предусмотренного ч. 9 ст. ст. $13^{15}$ КоАП РФ, должен определяться через исключение предмета преступления, предусмотренного ст. $207^{1}$ УК РФ. По нашему мнению, текст уголовно-правовой нормы с точки зрения юридической техники является неудачным, так как признаки предмета преступления, предусмотренного ст. $207^{1}$ УК РФ, фрактически учтены в тексте нормы об административном правонарушении («угроза причинения вреда жизни или здоровью, угроза общественной безопасности»). Необходимо изъять повторяющиеся признаки из текста ст. $13^{15}$ КоАП РФ.

Еще одно различие состоит в описании обстановки и средств совершения деяния. Судя по буквальному толкованию ст. $207^{1}$ УК РФ, деяние совершается публично и адресуется группе или неограниченному кругу лиц, при этом выражено в любой доступной для них фрорме (например, в устной, письменной, с использованием технических средств). В составе административного правонарушения признак публичности ограничен исключительно использованием СМИ и сети Интернет.

Стоит признать, что границы составов преступления и административного правонарушения (соответственно, ст. $207^{1}$ УК РФ, ч. 9 ст. $13^{15}$ КоАП РФ) 
являются размытыми и порождают межотраслевую коллизию, в результате чего правоприменитель при квалиорикации деяний дезориентируется. Анализ практики привлечения лиц к ответственности подтверждает, что фрактически одно и то же деяние может быть квалифицировано и как уголовное деяние, и как административное правонарушение [8]. Так, уголовное дело по ст. $207^{1}$ УК РФ было возбуждено в отношении блогера Александра Торна после публикации им видеоролика в социальной сети «Твиттер», в котором он в сатирической фрорме сообщил, что коронавирус COVID-19 был создан в государственном научном центре «Вектор», после чего путем взрыва умышленно распространён на территории России и КНР [9]. Причем смысловая нагрузка ролика была явно развлекательная, а не информационная. Приведу другой пример. Так, в Самарской области жительница г. Тольятти была привлечена к административной ответственности по ч. 9 ст. $13^{15}$ КоАП РФ за распространение в комментариях в одной из популярных соцсетей ложной информации о фракте смерти ребенка в Тольятти от коронавирусной инфекции. Она пояснила, что узнала информацию от незнакомой женщины в общественном месте. Поддавшись панике, женщина решила распространить непроверенную инорормацию, не удостоверившись в правдивости полученных сведений [10].

Смежным по отношению к преступлению, предусмотренному ст. 2072 «Публичное распространение заведомо ложной общественно значимой информации, повлекшее тяжкие последствия» УК РФ, является административное правонарушение, закрепленное в КоАП РФ в ч. 10 ст. 1315 «Распространение в средствах массовой информации, а также в информационно-телекоммуникационных сетях заведомо недостоверной общественно значимой информации под видом достоверных сообщений, повлекшее создание помех фрункционированию объектов жизнеобеспечения, транспортной или социальной инфраструктуры, кредитных организаций, объектов энергетики, промышленности или связи, если эти действия лица, распространяющего информацию, не содержат уголовно наказуемого деяния». В силу схожести предмета посягательства в виде общественно значимой инорормации разграничивать данные составы необходимо по объему и характеру наступивших общественно опасных последствий. Здесь законодатель также использует прием «исключения преступного».

Такое конструирование новых уголовно-правовых норм подтверждает, что законодатель не смог учесть возможные проблемы правоприменения. Факты наличия недостатков подтверждаются тем, что уже в первый месяц действия новых статей Верховный суд РФ в двух обзорах пытался разрешить спорные вопросы правоприменения.

Подводя итог вышесказанному, можно заключить, что введение в УК РФ статей $207^{1}$ и $207^{2}$ и внушительный рост числа уголовных дел показали включенность уголовно-правового регулирования во внутренние политические процессы. Для полезных целей бороться с дезинформаци- 
Баландин В. И.

ей и предупреждать панику населения государственная власть выбрала не лучшие инструменты: плохо сорормулированные и недостаточно обоснованные уголовно-правовые запреты. При этом не учтено, что распространение недостоверной инорормаци, создающее угрозу жизни и безопасности граждан или наступление иных тяжких последствий, в России Уже многократно криминализировано (ч. 3 ст. 212 , ст. $207,128^{1}, 205^{2}, 280,280^{1}$, 282 и $354^{1}$ УК РФ).

Предлагаю следующее:

Во-первых, необходимо изменить ст. $207^{1}$ УК РФ, учитывая проблему разграничения преступления и аналогичного административного правонарушения. На мой взгляд, оснований для криминализации данного деяния с такой широкой диспозицией недостаточно. В качестве решения проблемы предлагаю конкретизировать состав преступления, дополнив его конструктивными признаками, влияющими на степень общественной опасности преступления. Такими признаками могут быть совершение деяния из хулиганских побуждений либо в целях дестабилизации деятельности органов власти. Конструктивным признаком может служить также совершение деяния в отношении объектов социальной инфраструктуры.

Во-вторых, так как по задумке законодателя общественная опасность рассматриваемых преступлений состоит в создании общественной паники, то стоит ограничить применение данных составов во времени, например при введении режима «Повышенной готовности» или объявления «Чрезвычайной ситуации». Решением может также служить введение административной преюдиции по таким делам, аналогично преступлениям, связанным с возбуждением ненависти и вражды. Однократное распространение общественно значимой заведомо ложной информации должно влечь административную ответственность по ч. 9-10 ст. $13^{15}$ КоАП РФ, а в случае повторности - уголовную ответственность.

В-третьих, правоприменителю следует, оценивая общественную опасность деяния, сначала рассмотреть возможность признания его малозначительности. В каждом случае необходимо определять, в чем выражается создание угрозы причинения опасных последствий. Также целесообразно сорормировать судебную позицию с системой критериев оценки достоверности общественно значимой информации и обстоятельств, представляющих угрозу жизни и безопасности граждан. $\mathfrak{K}$ таким критериям, например, можно отнести источник информации, степень его авторитетности, анонимность или открытость. Исходя из проанализированных материалов дел, можно сделать вывод, что любая информация от неофициального или анонимного источника считается недостоверной, пока не подтверждена государством.

В-четвертых, необходимо устанавливать причинно-следственную связь между публикацией недостоверных сведений и возможностью наступления указанных в законе угроз или фрактически наступившими 
опасными последствиями, а также выявлять субъективное отношение лица к последним. Любой человек имеет право на высказывание собственного мнения, даже если оно не соответствует объективной действительности или официальной позиции властей. Кроме этого, любой человек имеет право на распространение своего мнения среди других лиц в публичной плоскости, соблюдая установленные ограничения в целях защиты интересов общественной безопасности. По соответствующим уголовным делам необходимо проведение лингвистической экспертизы вцелях определения речевой направленностивысказывания иустановления признака заведомо ложного характера распространяемой информации.

\section{Ссылки}

1. Кленова Т. В. Квалификация преступлений и уголовная политика // Государство и право. 2012. № 4. С. 55-63.

2. Эпидемия фейков: борьба с коронавирусом как угроза свободе слова: доклад Международной Агоры. URL: https://www.agora.legal/news/2020.06.15/DokladMezhdunarodnoi-Agory-\%C2\%ABEpidemiya-feikov-borba-s-koronavirusomkak/1039 (дата обращения: 23.02.2021).

3. Жеребкин В. Е. Логический анализ понятий права. Киев: Вища школа, 1976. $150 \mathrm{c}$.

4. Пудовочкин Ю. Е. Оценка судом общественной опасности преступления: научно-практическое пособие. М.: РГУП, 2019. 221 с.

5. Честнов И. Л. Общественная опасность преступления в постклассической перспективе // Образование и наука: Вопросы теории и практики. 2015. № 1. C. $239-242$.

6. МВД возбудило с начала года 37 уголовных дел о распространении фейков во время пандемии. URL: https://tass.ru/obschestvo/10300833 (дата обращения: 23.02.2021).

7. Первое в России уголовное дело о «коронавирусном» фейке возбуждено в Петербурге. URL: https://novayagazeta.ru/articles/2020/04/08/84786-boleznennoesostoyanie (дата обращения: 23.02.2021).

8. Обзор по отдельным вопросам судебной практики, связанным с применением законодательства и мер по противодействию распространению на территории Российской Федерации новой коронавирусной инфекции (COVID-19) № 1, утвержден Президиумом Верховного Суда Российской Федерации 21 апреля 2020 года. URL: https://www.vsrf.ru/files/28856/ (дата обращения: 23.02.2021).

9. Возбуждено уголовное дело по фракту распространения ложной информации о коронавирусной инфекции. URL: https://sledcom.ru/news/item/1454213/ (дата обращения: 23.02.2021).

10. Жительницу Тольятти привлекли к ответственности за распространение фрейковой информации./ URL: https://xn--b1aew.xn--p1ai/news/item/20259950/ (дата обращения: 23.02.2021). 